\title{
Flavor Chemistry of Ethnic Foods
}




\section{Flavor Chemistry of Ethnic Foods}

Edited by

\section{Fereidoon Shahidi}

Department of Biochemistry

Memorial University of Newfoundland

St. John's, Newfoundland

AIB $3 X 9$ Canada

Chi-Tang Ho

Department of Food Science

Cook College

Rutgers, The State University of New Jersey

P.O. Box 231

New Brunswick, NJ 08903-0231

Springer Science+Business Media, LLC 


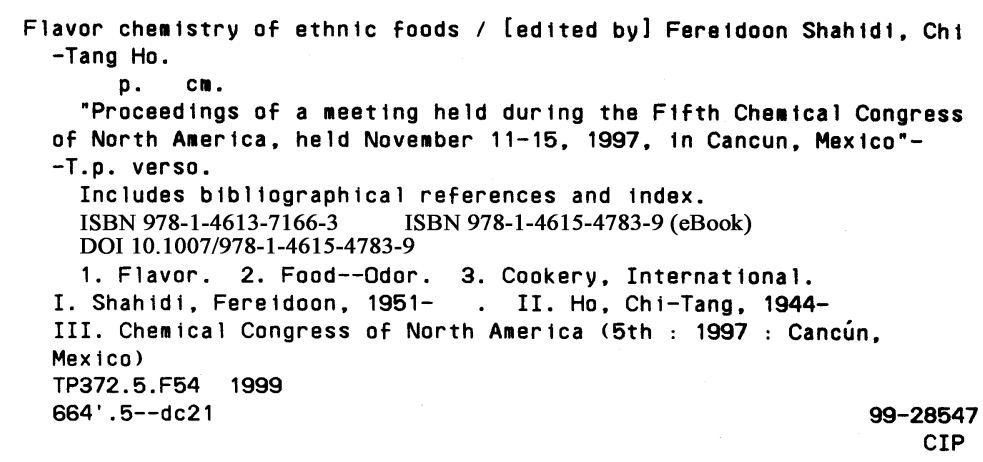

Proceedings of a meeting held during the Fifth Chemical Congress of North America, held November 11-15, 1997, in Cancun, Mexico

\section{ISBN 978-1-4613-7166-3}

(C)1999 Springer Science+Business Media New York

Originally published by Kluwer Academic/Plenum Publishers in 1999

Softcover reprint of the hardcover 1st edition 1999

$\begin{array}{llllllllll}10 & 9 & 8 & 7 & 6 & 5 & 4 & 3 & 2 & 1\end{array}$

A C.I.P. record for this book is available from the Library of Congress.

All rights reserved

No part of this book may be reproduced, stored in a retrieval system, or transmitted in any form or by any means, electronic, mechanical, photocopying, microfilming, recording, or otherwise, without written permission from the Publisher 


\section{PREFACE}

Flavor is an important quality characteristic of all foods. Both odor- and taste-active components are involved. Although perception of flavor is a chemically-derived phenomenon, a flavor's acceptability and desirability is highly affected by the cultural background and ethnic diversity of the consumers. On this basis, there are distinct differences and particularities in the ingredients as well as the methods of preparation of foods in different regions of the world, and these are also affected by the specific environment, culture, and ethnicity of the people. Changes in the flavors of foods, induced by processing, are also important factors affecting their diversity and characteristics. The use of different types of sauce, such as soy sauce, tomato sauce, and fish sauce, as well as condiments and spices, is of particular importance in defining the cultural and international nature of prepared foods. The source of raw material, particularly when they are available only in certain parts of the world, can also have a profound effect on the availability and popularity of such products. The availability of better and faster modes of transportation and the migration of individuals, each resulting in the intermingling of different cultures, have allowed production of a new generation of prepared foods such as American-Chinese, among others.

The present monograph assembles a collection of scientific contributions on flavor and chemistry of international foods presented during the $5^{\text {th }}$ Chemical Congress of North America, held in November 1997, in Cancun, Mexico, or subsequently solicited by the editors. We are grateful to the authors for their outstanding cooperation and contributions that made the production of this state-of-the-art monograph possible.

Fereidoon Shahidi Chi-Tang Ho 


\section{CONTENTS}

1. Flavor and Chemistry of Ethnic Foods: An Overview $\ldots \ldots \ldots \ldots \ldots \ldots \ldots$ F. Shahidi and C.-T. Ho

2. Flavor Components of Shoyu and Miso Japanese Fermented Soybean

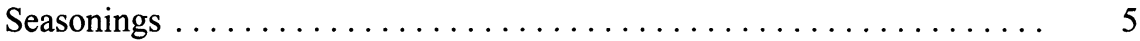

Akio Kobayashi and Etsuko Sugawara

3. Flavor Characteristics of Indonesian Soy Sauce (Kecap Manis) . . . . . . . 15

A. Apriyantono, H. Husain, L. Lie, M. Jodoamidjojo, and

N. L. Puspitasari-Nienaber

4. Volatile Compounds Isolated from $\mathrm{Sa}$ Cha Sauce $\ldots \ldots \ldots \ldots \ldots \ldots \ldots$

Chao-Yin Tai and Chi-Tang Ho

5. Formation of Volatile Acids during Fermentation of Fish Sauce ...........

Norlita G. Sanceda, Emiko Suzuki, and Tadao Kurata

6. Flavor Chemistry of Selected Condiments and Spices Used in Chinese Foods . .

Chi-Tang Ho, Jiangang Li, and May-Chien Kuo

7. Character-Impact Aroma Components of Coriander (Coriandrum sativum L.)

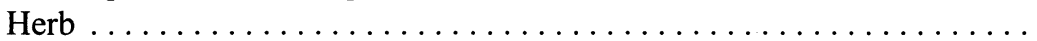

K. R. Cadwallader, R. Surakarnkul, S.-P. Yang, and T. E. Webb

8. Wasabi, Japanese Horseradish, and Horseradish: Relationship between Stability and Antimicrobial Properties of Their Isothiocyanates ...........

Hideki Masuda, Yasuhiro Harada, Toshio Inoue, Noriaki Kishimoto, and Tatsuo Tano

9. Flavor Characteristics and Stereochemistry of the Volatile Constituents of

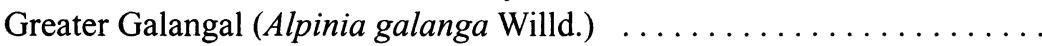

Kikue Kubota, Yuki Someya, Yoshiko Kurobayashi, and Akio Kobayashi

10. Volatile Composition of Pandan Leaves (Pandanus amaryllifolius)

J. Jiang 
11. Emission of Blanched Broccoli Volatiles in Headspace during Cooking ....... Heikki Kallio, Päivi Raimoaho, and Tuomas Virtalaine

12. Flavor of Kweni (Mangifera odorata Griff), an Exotic Tropical Fruit .........

C. H. Wijaya, A. Apriyantono, T. May, H. Raharja, and T. A. Ngakan

13. Use of Electronic Nose Technology to Examine Apple Quality .......... Arthur M. Spanier, John C. Beaulieu, Karen L. Bett, and Ken Gross

14. Flavor and Chemistry of Uncured and Cured Meat of Harp Seal (Phoca

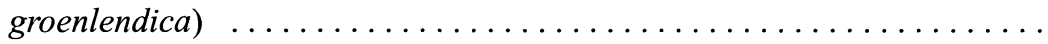
Fereidoon Shahidi and Ming-Xia Lin

15. Characterization of Volatile Aldehydes and Pyrazines in Pan-Fried Zousoon ... Tzou-Chi Huang, Yea-Chyi Chiou, and Chi-Tang Ho

16. Changes in Flavor-Related Compounds in Meat Treated with Organic Acids ... Héctor Escalona, Sharon K. Ogden, Isabel Guerrero, and Andrew J. Taylor

17. Flavor Differences Due to Processing in Dry-Cured and Other Ham Products

Using Conducting Polymers (Electronic Nose) $\ldots \ldots \ldots \ldots \ldots \ldots$ 169 Arthur M. Spanier, Monica Flores, and Fidel Toldrá

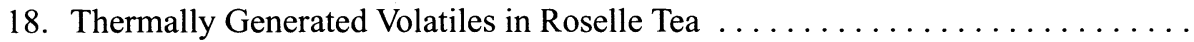
Pi-Jen Tsai, Tzou-Chi Huang, Shyh-Hung Chen, and Chi-Tang Ho

19. Phenolic Compounds as Astringent Factors in Black Tea Liquors . . . . . . . . E. Ponce and A. J. Taylor

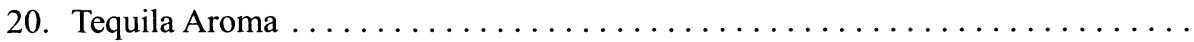
Mercedes G. López

21. The Formation and Release of Odor Active Compounds during Oxidation of

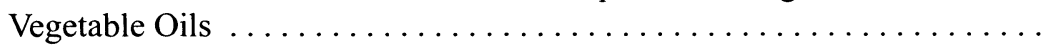

J. P. Roozen, P. A. Luning, and M. A. Posthumus

22. Influence of Seed Roasting Process on the Changes in Volatile Compounds of

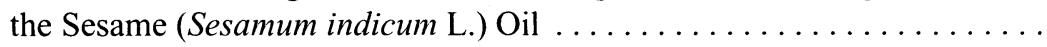

Su Noh Ryu, Seong Min Kim, Junwu Xi, and Chi-Tang Ho

23. Volatile Components Formed from Various Sugars with $\beta$-Alanine in Actual

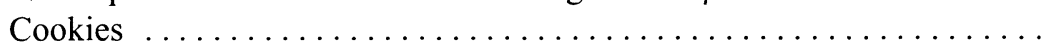

Sukie Nishibori, Toshihiko Osawa, and Shunro Kawakishi

24. Aroma Formation in Dried Mullet Roe as Affected by Lipoxygenase ........

Bonnie Sun Pan and Chia-Ming Lin

25. Volatile Compounds Identified in Preserved Duck Eggs

Jianhong Chen and Chi-Tang Ho 